\title{
Learning Styles: Factors Affecting Information Behavior of Thai Youth
}

\author{
Jutharat Changthong (corresponding author) \\ Information studies Program, \\ Khon Kaen University, Thailand \\ jutharat.su@gmail.com \\ Lampang Manmart \\ Faculty of Humanities and Social Sciences, \\ Khon Kaen University, Thailand \\ lamman@kku.ac.th \\ Chollabhas Vongprasert \\ Faculty of Humanities and Social Sciences, \\ Khon Kaen University, Thailand \\ chat045@yahoo.com
}

\begin{abstract}
This study aimed to investigate the relationship between the different learning styles of Thai youths and their information behavior at a time where rapidly developing information and communication technology has affected the informational environment. This was a qualitative research study which used theoretical sampling to select study areas and involved thirty participants in their fourth, fifth and sixth year in a large secondary school. The Grasha-Riechmann Student Learning Style Scale was used to determine the students' learning styles. The results indicated that learning styles affected information behavior only slightly because the collaborative style of Thai youths was to divide the task and work individually. Information behavior was best examined at a personal level.
\end{abstract}

\section{INTRODUCTION}

Information behavior is becoming a fundamental and strategic aspect of intelligent citizenship. For organizations, understanding information behavior helps to support information systems design and enhance the strategic scanning capability of their members. For individuals, it is increasingly important to be "information literate." An information literate person recognizes the need for information, and knows how to search, evaluate and use what is found effectively. It is a crucial part of their daily lives. For information professionals, this ability helps them in the design and delivery of information in many different contexts. Understanding information behavior patterns and the factors that affect them, will help in the identification and removal of obstacles to information use. People need to use this information for planning, analyzing, problem solving and learning. Additionally, some researchers are studying individuals' information behavior, especially that of influential 
people in society, for example doctors, scientists and lawyers, due to the potential effect of their behavior upon society (Case, 2007). These studies relating to information behavior have increased every year, including studies of the information behavior of children and teenagers.

This potential effect on society is especially true for those who have been educated in their primary stages, similar to the adolescent development scheme which has been implemented in some developing countries, for example members of the Organization for Economic Cooperation and Development (OECD) (Office of the Education Council, 2007, pp. 19-20). There are legitimate concerns about the development of adolescents because they form a major part of the structure of people skills development in the industrial segment. Grooming adolescents throughout their education with an aim to help their countries become technological leaders and reap economic benefits is an important belief. These studies have highlighted the unsuccessful development of some groups of Thai adolescents. As an example, the assessment of the study quality of Thai primary education by The Office for National Education Standards and Quality Assessment reported that the analytical skills of the examined students were very low. This implied that Thai youth who had finished compulsory education were not prepared for quality citizenship, nor were they ready to face competition in the future (Office of the Education Council, 2007).

Information behavior is dynamic and varies according to the factors that influence the information seeker (Wilson, 1999 \& 2000; Todd, 2003). Examples of these factors that may support or undermine information behavior include demographic differences such as gender or age, population-specific features such as education level and personality, and environmental factors such as workplace, economic status, and social and cultural rights. For young people who are in the education system, a very important unique feature we found is learning style: these cover physical characteristics, feelings, how the individual gets to know and organize information, response to stimuli, and interaction with the instructor, friends and the learning environment (Grasha, 1996).

Learning style is an important element of learning, particularly in an environment of managed education that emphasizes student centered learning (Department of Curriculum and Instruction Development, Ministry of Education, 2001). In addition, there are also some research results showing the relationship between learning styles of students and their levels of achievement in studies (Raenak, 2003; Uthasan, 2007; Bahar, 2009). Some research have also found that if a teacher does not create conditions that are suitable for learners, then the achievement is lower in that group than in a group that receives education that is consistent with the conditions which participants like (Department of Curriculum and Instruction Development, 2001). Therefore, learning style is a factor that educators agree is significant for young people in an education system, and some information behavior scholars agree that it is likely to have a relationship with information behavior (Marchionini, 1995; Kuhlthau, 2004; Weiler, 2004; Heinstrom, 2005). If they can fine-tune the relationship between learning styles and information behavior then they can better understand the information behavior of young people. However, there is still little or no research in Thailand about the relationship between information behavior and learning styles. Abroad, only one piece of research can be found (Heinstrom, 2005), while in Thailand, researchers are most likely to use the Grasha and Riechmann instrument (Hruska-Riechmann \& Grasha, 1982) to identify learning styles (Department of Curriculum and Instruction Development, 2001).

Researchers are interested to understand the learning styles of Thai youth, which are relevant to the everyday information behavior of young people in an electronic environment. It is useful and important to learn more about the information behavior of young people and identify theories and behavioral patterns that can be used to describe and explain their 
behavior in detail. Knowledge about learning styles which may affect the information behavior of youths will be used as a basis for the development of the young people, especially in the area of learning development and development of lifelong learning skills. The teaching of these skills and the management of information technology and information sources that are appropriate for young people are important responsibilities for information professions and those involved in youth work. If course providers, instructors, providers of information technology services, and information designers understand the information behavior of young people, it is hoped that they will tailor courses and information sources and services to the students' needs and their behavior patterns.

\section{CONCEPTUAL FRAMEWORK}

Two theoretical frameworks have been used in this study: an information behavior model and a learning style model.

\section{Information Behavior Model}

This research used Wilson's information behavior model as the conceptual framework (Wilson, 1981, $1997 \&$ 2000). It is a general information behavior model without presentation of detailed behavior. It is used to present the typical concepts and the relationships of various concepts of information behavior consisting of information need, information search and information use. Wilson's (1981) model identified the influence of the context of information need, comprising individual characteristics, social roles and personal environment. Taking into account the fact that some Thai social values have changed over the years, such as the use of singers or television stars as role models, this new social environment has also influenced the information behavior of adolescents (Soonthorndhada, et al., 2005). This study was therefore founded on the primary perspectives of information and communication Technology (ICT) plus the alteration of social values, working under the assumption that most people can easily acquire and access information. It has been pointed out that information behavior should be studied as a whole, including information needs, information search and information use.

Information needs are not obvious, but are discoverable by implication from behavior reports so we decided to follow Wilson's (1981) model which showed that information needs occur to support the functional demands of individuals and social situations. This study worked on assumed situations for adolescents in the education world and allowed the participants to explain their acquired information situations and how those conditions were suited to their purposes. This also helped in the categorization of the information resources demand and format.

This study focused on the information seeking processes in four steps:

1. defining the problem,

2. selecting sources of information,

3. accessing information and

4. evaluating the information.

Participants were encouraged to express in their own words their experiences when seeking information. Next, they found out how to access that information and how to locate the sources prior to making decisions, and finally how to evaluate the received information.

Information use behavior patterns can be inferred from an analysis of the behavior of adolescents with similar information needs. It would be necessary to discover what adolescents did to satisfy their information demands and what the outcome was after doing so. 


\section{Learning Styles Model}

Learning styles and their relations with information behavior was investigated in this study. We employed the Grasha-Riechmann Students Learning Styles Scales (GRSLSS). This model was developed in the early 1970s (Hruska-Riechmann \& Grasha, 1982). The GRSLSS was selected to assess the students' learning styles because it was primarily designed to be used with senior high school students. The GRSLSS also promotes understanding of students' learning styles in a broad context by spanning six categories. The six social learning styles identified in this model are - Independent, Dependent, Competitive, Collaborative, Avoidant and Participant. The six learning styles are described in Table 1 (Ritchie, 2006). The model has been successfully used in several cultural contexts (Diaz \& Cartnal, 1999; Uzuntiryaki, 2007; Mahamod, 2010; Gujjar \& Tabassum, 2011). The Thai version questionnaire was validated through pilot testing on 30 students and the internal consistency of this questionnaire was assessed using Cronbach's alpha coefficient which was found to be 0.865 .

\section{Table 1. Grasha-Riechmann Learning Styles Dimensions}

\begin{tabular}{ll}
\hline Dimension & Characteristic of Learner \\
\hline 1. Independent & $\begin{array}{l}\text { Like to think for themselves and confident in their learning abilities. } \\
\text { Prefer to work alone. }\end{array}$ \\
2. Dependent & $\begin{array}{l}\text { Show little intellectual curiosity and learn only what is required. Look } \\
\text { for authority figures for specific guidelines on what to do. }\end{array}$ \\
3. Competitive & $\begin{array}{l}\text { See the classroom as a win-lose situation in which they must win and } \\
\text { enjoy competitive activities. }\end{array}$ \\
4. Collaborative & $\begin{array}{l}\text { Work well with others and enjoy cooperative learning and working } \\
\text { groups. }\end{array}$ \\
5. Avoidant & $\begin{array}{l}\text { Do not want to learn the content, do not enjoy learning and avoid taking } \\
\text { part in course activities }\end{array}$ \\
6. Participant & $\begin{array}{l}\text { Eager to learn course content, enjoy learning, and take responsibility for } \\
\text { his/her own learning. }\end{array}$ \\
\hline
\end{tabular}

\section{METHODOLOGY}

\section{Use of Grounded Theory in Analyzing Information Behavior}

In order to develop a theoretical understanding of the information behavior of Thai adolescents, we studied the phenomenon through the lens of a qualitative research paradigm. A grounded theory approach was adopted. Grounded theory is an inductive investigative process in which the researcher formulates a theory about a phenomenon by systematically gathering and analyzing relevant data as it occurs in a real situation (Glaser \& Strauss, 1967). Pace (2004) outlined the four main stages of developing a grounded theory:

As with much qualitative research, data collection and data analysis occurred simultaneously in this study. A theory was derived from the data using a constant comparative method of analysis with four stages: generating categories and their properties; integrating categories and their properties; delimiting the theory; and writing the theory. (p. 337) 


\section{Selecting the School}

A school that satisfied the criteria was selected using a theoretical sampling method. It was a large secondary school in the west of Thailand which met the research objectives because of its environment and ICT infrastructure. All classrooms were equipped with televisions and cable TV. There were also other student learning centers such as computer labs, science and foreign language labs and a school theater. Moreover, the virtual learning environment, which was managed by an open source course management system, gave students access to more materials and also greater communication with their teachers. Students could access the Internet in every building. In addition, the school library had received an award for excellent service.

\section{Key Informants}

The theoretical sampling process involved selecting adolescents without particularly advanced qualifications, but who met the research objectives in that they were Thai students in their fourth, fifth or sixth year in a large secondary school, aged between 15 and 20. These students were interviewed, and the information collected was analyzed in detail. This was followed by the conception and grouping stage, where the concepts were connected and primary conclusions were arrived at. At this point, the students who had given different responses from the norm (negative case) were identified by referring to the mentioned conclusion. This involved selected adolescents who had different attributes, for example, gender, study outcomes, fields of study and residential areas. However, in order to cover all the characteristics of the youth in question and also to cover new aspects complying with the original data by using the matrix method, the interviews continued, and we stopped only when some pattern of behavior presented itself repeatedly or when no more new data were found. This is called "Theoretical Saturation." There were a total of 30 students who became interviewees for this study.

\section{Data Collection}

In-depth interviews were used to obtain data for this study. This is to encourage the subjects to reveal their experiences, performance, feelings and attitudes relating to information behavior in detail. The interview guidelines consisted of 20 questions. However, the possibility of expanding each question to sub-questions as required was open to the researchers. The interviews took place in the premises of the school and responses were recorded digitally. In addition to the qualitative interviews, documents such as school information, assignment sheets and curriculum documents were also examined and their content analyzed. The combination of a variety of data gathering techniques allowed for a more complete picture of information behavior of the adolescents to emerge through triangulation.

\section{Learning Style Study}

This part of the study was carried out using a questionnaire instrument.

\section{Population and Sampling}

The target population of the study included fourth, fifth and sixth year students during the 2010 academic year. According to Krejcie and Morgan (1970), 312 responses were required to achieve a $95 \%$ confidence interval. The breakdown of the total number of students are as 
follows: 102 from the fourth year, 108 students from the fifth year and 102 students from the sixth year. Group sizes varied between the groups because the numbers of students in each year were different.

\section{Research Instrument}

The Thai version of GRSLSS was used to identify the preferences students had for interacting with peers and instructors in their classroom settings (Department of Curriculum and Instruction Development, Ministry of Education, 2001). It consists of 60 questions, divided into 6 groups of ten questions to determine the six learning style dimensions. Each question uses a 5-point Likert scale for the participant to select.

The researchers initially used the 60-item GRSLSS to assess the learning styles and continued into the in-depth interview. They found this operation too time consuming. Some students answered questions in short sentences without thinking about their responses. Some participants simply did not have enough time during the interview for the researchers to glean the necessary data about their information behavior. The researchers therefore needed to improve the data collection process by initially analyzing the learning styles of the students in general. Then, by using certain attributes of each learning style from a summary of the questions and by checking out all the 30 students' learning preference, the process of identifying the learning styles of 30 key informants took less time-approximately 5 minutes.

\section{Administration of Data Collection}

Researchers had asked for cooperation from the head teachers responsible for the three class years to distribute and collect 312 questionnaires. All the questionnaires were returned, accounting for a full $100 \%$ response rate.

\section{Data Analysis}

The learning style of each youth was determined by analyzing the overall scores of each individual learning format. It was concluded that the young people liked the format with the highest score in each case.

\section{FINDINGS}

From studying the information behavior of youths, which comprised of - information need, information seeking and information use, it was found that information seeking is related to the learning styles of juveniles with behavioral details described below.

\section{Information Seeking Behavior of Thai Youth}

Researchers conducted interviews with youths using an ongoing situation, starting from one set of circumstances which demanded certain information in the first place. The subjects were encouraged to express in their own words their experiences when seeking for information in four main ways.

\section{Defining the Problem}

Students often defined problems themselves by using keywords from the assignments in a quick search on the Internet. Working in teams, they would begin with discussion and brainstorming to better understand the assignment among their members. Next they will form 
a working agreement and concept. After that, they allocated work based on each individual's abilities and skills, for example, information seeking and presentation skills. The group member who had the highest score was always assigned to be responsible for information search. They would initially access the Internet as their first source. In the personal information search area, for example, looking for the profiles of singers or stars, they would define the problems encountered by the search guidelines themselves. They would subdivide the issues and use them as keywords for Internet searches, and they then naturally visited their favorite websites.

\section{Selecting Sources of Information}

The information resource which the young people used the most was the Internet. The reason was that they felt confident with the Internet and trusted it to contain all the useful information that they needed. This information may come in large quantities in many formats, such as text, images, sound and multimedia, for selection. It was also possible to copy and forward information acquired from the Internet speedily and simply. It was convenient to access the Internet at home because most of them had computers and Internet access in their homes. If they needed to use it at school, Internet access was available at the computer centre or the Internet café. Their reasons for turning down access to the library were because of the complications involved, such as limited access during working hours, and the requirements for membership cards and finger scans. However, they would go there when the teacher assigned them to, or they couldn't find the required information on the Internet.

\section{Information Access}

The participants chose Google as their preferred search engine to assist them to get the required information quickly since they believed that it could search for everything easily and in just one easy click. They would use the teacher's assignment as the keywords to search and access the first result presented on the screen because they believed that it could provide them with much of the required information. They were still happy to use it even if it was sometimes unsuccessful in its search. This was because it led them to some related results. Sometimes other keywords displayed could provide them with new keywords to continue to search in Google. They continued their search until they were unable to find the required information, at which point they would turn to their teachers for some supplementary explanations or would request help from friends. The teachers would then suggest recommended websites or going to the library. Moreover, they tended to go directly to their favorite websites with confidence that they would contain all of their required information.

\section{Evaluation of Information}

When they searched for information on the Internet, they began with evaluating information sources by observing the website names first, i.e. they would use a reliable online encyclopedia like Wikipedia. Then they analyzed the information from the websites, considering whether or not it was related to their assignments. If there was plenty of consistent information, they selected the texts which were short and easy to read; they avoided long ones which they did not want to read through. After that, they considered whether they had received sufficient information or not, and, if so, they discontinued their search. If not, they repeated the whole process or changed the source or the method of access. 


\section{Learning Style of Thai Youth}

The results relating to the learning styles of the youths are divided into two parts: learning styles in general and the learning styles of the key informants as follows:

\section{The Learning Styles of Young People in General}

From the sample of 312 students, it was found that the collaborative style was the most common with $43 \%$ participants; next was a dependent learning style with $21 \%$ participants; finally the avoidant learning style accounted for $4 \%$ of the participants.

\section{The Learning Styles of Key Informants}

A study of the learning styles of the 30 key informants found that their learning styles were consistent with those of the students in general. A collaborative style was the highest ranked with 25 people. The youths were asked how they liked to work when asked to cooperate with teachers and friends to do homework. It seemed that when instructed to do homework by a teacher, they immediately thought about going home to do the necessary research on their own computers, since they all had access to the Internet at home. The process that this group used to find information from the Internet was to find the information they wanted from Google by using the keywords from their homework topics. In addition, there were also occasional attempts to change to a new search in order to obtain results that differred from the original, including attempts to find information from multiple sources. It would appear from this research that the model of collaborative learning of this group was not one built on sharing the learning process with each other, but to collaborate by dividing the necessary work amongst themselves to reduce the burden on each individual, then pooling the results in the end to accomplish the original task. This interview excerpt illustrates this point:

Actually, I like group project. We can help each other. I think I can't do a project in time alone. [female, sixth year, high GPA]

Besides these students, five more key informants from the sample were found to prefer a dependent style, rather than a collaborative style. They did not like doing homework, and worked only when ordered to by a teacher. When a situation arose where work was needed to be done by a group of students, each individual depended on others in the group to do the work. It was also found that the students produced only the bare minimum required by their teachers.

When information need was necessary with this group, it was found that they still tried to rely on teachers or more intelligent friends to provide help and support even during exams. When thinking of the entrance exams to university, they begged those in their sixth year, who were their seniors for information, although the older students often could not answer their questions. Furthermore, it was found that the students in question were still unlikely to research for information in libraries unless as a last resort. When it came to Internet research, they simply used the information given to them by their teachers as keywords for Google searches. When they found the information that they wanted, they would select the shortest, easy-to-understand information and they would not look for other sources of information. They used only keywords to find information. This group of students preferred to search for information from the Internet rather than other sources, especially for information in which they were interested. They were therefore impressed and felt that they could find any information that they needed. 
I use Google to search for my homework. I like typing one short term because it brings me more search results. Among the results, I always choose a short one because it's easy to understand. [female, sixth year, low GPA]

\section{The Relationship Between Information Behavior and Learning Style}

Youths with collaborative learning styles are a little different to those with dependent learning styles when it comes to information seeking behavior. Thai students with a collaborative learning style divide the tasks and work individually, while some with dependent styles prefer to ask experts when seeking information. Most information behavior, however, is still similar.

\section{DISCUSSION}

\section{Information Behavior of Thai Youth}

In this study, details of the information behavior clearly show that the development of ICT has affected access to information in the ways that young people use the Internet, since they believe that the Internet has all the information they need. On the other hand, they are not interested in going to a library because they feel that it is too complicated, thus the library is not a reliable option for finding information anymore. On the other hand, the Internet has become the users' reliable source of information but they must have initial guidance from a teacher or librarian to help them to find the information. This suggests that the role of the teacher has become that of a guide to information sources for young people. Because of this change, the image of a library has also changed. The details of the behavior involved increase the amount of information available. Wilson (1997) described only the categories of information and information sources, such as documentaries on radio or television, but he did not describe the details of the behavior of the information as Wilson (2005) explained:

The value of a model of this kind lies in drawing the attention of the researcher to the totality of information behavior and showing how a specific piece of research may contribute to an understanding of the whole. It has no pretensions to explaining everything to do with human information behavior. (p. 35)

This study tries to propose explanations for how and why certain behaviors occur, with explanations that are grounded in the data.

\section{Learning Style of Thai Youth}

Our survey of learning styles found that a high percentage of students prefer a collaborative learning style (43\% of participants), which differs from other researchers' findings that most Thai youths prefer a participation learning style (Raenak, 2003; Uthasan, 2007). However the nature of the collaborative learning style that was found in most of the youngsters from the study is still consistent with the development of the students in adolescence who can build relationships with colleagues of the same or different genders as well as with more mature people (Kowtrakul, 2005). Moreover, in the pattern of collaborative learning styles, there are also features of the high level relationship between people that allows students to show off, make comments or exchange opinions with each other between friends and teachers.

However, the study results indicate that the learning collaborative style of Thai youth when seeking information is different from the description of Grasha and Riechmann (Grasha, 1996) which stated that students who have a collaborative learning style will cooperate to share the learning. This is based on the classroom as a source of social interaction and learning, and cooperation between teachers and friends. However, the style of cooperation of 
Thai youth discovered by this study involves collaboration in order to break down the work amongst the group to reduce the burden, by dividing the work by function such as report writing and searching for information. This result reveals differences in the details of learning patterns that are not found in previous research on learning patterns of Thai youth. This may be explained by the fact that Grasha and Riechmann, in past research, used test measurements as the only source of data.

\section{The Influence of Learning Style on Information Behavior}

Although the varying types of information behavior in this report demonstrated differences in learning styles, it did not provide a clear overview of the behavior of different groups. The relationship between learning styles and information behavior differs slightly in each case. The collaborative style, based on the conceptual frame of the original Grasha and Riechmann work, suggests that students cooperate to share learning, but the cooperation of Thai youths from this research differed from this model because the youths did not have the ability to cooperate to learn together. Instead, they only intended to divide the work and to reduce each individual's burden. The information behavior of young people constitutes the information behavior of individuals, not the behavior of a group. However, the study results are consistent with Heinstrom's (2005) even though the conceptual framework for measuring learning styles differs. The research found that young people who have different learning styles have different information seeking behavior.

\section{CONCLUSION AND STUDY LIMITATIONS}

The main purpose of this study was to investigate the relationship between the learning styles of Thai students and their information behavior. The findings indicate that learning style slightly affects information behavior. Thai students with a collaborative learning style tend to divide the task, and work individually on the subtasks.

The use of qualitative analysis techniques can give details of information behavior from the perspective of the participants (Thai youths); unlike studies using questionnaire surveys which usually produce overall results but cannot identify the details or provide a description of each type of behavior. In this study, data was collected using a few methods, allowing for a more complete picture of information behavior to emerge through triangulation.

A study limitation is that the researchers may have been influenced by their literature review and personal experience in developing the conceptual framework. For example, Wilson's model of information behavior was used to guide the collection of qualitative data, and the interpretation of the data. Interpretation by other researchers who have had different experiences and academic backgrounds may offer different perspectives.

In addition, this study used a Grounded Theory approach to develop a theory. Theory testing must be conducted in a broader context, with larger groups of participants. This study focused on a sample of young people who used ICT within a similar context, since the majority of the youths lived in urban areas and had ready access to ICT. Therefore, in the future, studies should examine information behavior in other groups of youths in different contexts, such as those who do not have ready access to ICT.

\section{REFERENCES}

Bahar, M. (2009). The relationships between pupils' learning styles and their performance in mini science projects. Educational Sciences: Theory and Practice, 9(1), 31-49. 
Case, D.O. (2007). Looking for information: A survey of research on information seeking, needs, and behavior (2nd ed.). New York: Elsevier.

Department of Curriculum and Instruction Development, Ministry of Education, Thailand. (2001). Teaching and learning styles. Bangkok: Department of Curriculum and Instruction Development.

Diaz, D. P., \& Cartnal, R. B. (1999). Students' learning styles in two classes: Online distance learning and equivalent on-campus. College Teaching, 47(4), 130-135.

Glaser, B.G., \& Strauss, A.L. (1967). The discovery of grounded theory: Strategies for qualitative research. New York: Aldine De Gruyter.

Grasha, A.F. (1996). Teaching with style. Pittsburgh, PA: Alliance.

Gujjar, A.A., \& Tabassum, R. (2011). Assessing learning style of student teachers at federal college of education. Procedia-Social and Behavioral Sciences, 30, 267-271.

Heinstrom, J. (2005). Fast surfing, broad scanning and deep diving the influence of personality and study approach on students' information-seeking behavior. Journal of Documentation, 61(2) 228-247.

Hruska-Riechmann, S., \& Grasha, A.F. (1982). The Grasha-Riechmann student learning style scales. In J. Keefe (Ed.), Student learning styles and brain behavior (pp. 81-86). Reston, VA: National Association of Secondary School Principals.

Kebede, G. (2002). The changing information needs of users in electronic information environments. The Electronic Library, 20, 14-21.

Kowtrakul, S. (2005). Educational psychology (6 ${ }^{\text {th }}$ ed.). Bangkok: Chulalongkorn University Press.

Krejcie, R.V., \& Morgan, D.W. (1970). Determining sample size for research activities. Educational and Psychological Measurement, 30, 607-610.

Kuhlthau, C.C. (2004). Seeking meaning: A process approach to library and information services (2nd ed). Westport: Libraries Unlimited.

Large, A., Beheshti, J., \& Rahman, T. (2002). Gender differences in collaborative Web searching behavior: An elementary school study. Information Processing and Management, 38, 427-433.

Mahamod, Z., Embi, M.A., Yunus, M.M., Lubis, M.A., \& Chong, O. S. (2010). Comparative learning styles of Malay language among native and non-native students. ProcediaSocial and Behavioral Sciences, 9, 1042-1047.

Marchionini, G. (1995). Information seeking in electronic environments. Cambridge: Cambridge University Press,

Office of the Education Council, Thailand. (2007). Education in Thailand 2007. Bangkok: Office of the Education Council.

Office of the Education Council, Thailand. (2007). Thailand education on the world stage 2007. Bangkok: Office of the Education Council.

Pace, S. (2004). A grounded theory of the flow experiences of Web users. International Journal of Human-Computer Studies, 60, 327-363.

Raenak, S. (2003). The effect of learning styles on English achievement of Mathayom Suksa five students in the school under the Department of General Education, Phetchabun. Unpublished Master's thesis-Educational Program in Curriculum and Instruction, Rajabhat Institute Phetchabun, Thailand.

Ritchie, L. (2006). Blueprint for learning: Construction of college courses to facilitate, assess, and document learning. Sterling, VA: Stylus. Retrieved October $20^{\text {th }}, 2014$, from http://labkom.stikom.edu/download/ebook/BlueprintForLearning\%20- 
$\% 20$ Constructing $\% 20$ College $\% 20$ Courses $\% 20$ to\%20Facilitate, $\% 20$ Assess, $\% 20$ and $\% 2$ 0Document\%20Learning.pdf

Shenton, A.K. (2004). Research into young people's information-seeking: Perspectives and method. Aslib Proceedings: New Information Perspectives, 56, 243-254.

Soonthorndhada, A., Kittisuksathit, S., Punpuing, S., Varangrat, A., Malhotra, A., Curran, S. R., \& Martin, S. B. (2005). Youth at odds: Thai youth's precarious in a globalized world. Nakhon Pathom: Institute for Population and Social Research, Mahidol University with International Center for Research on Women and Office of Population Research, Princeton University.

Todd, R.J. (2003). Adolescents of the information age: Patterns of information seeking and use and implications for information professionals. School Libraries Worldwide 9, 2746.

Uthasan, S. (2007). Comparison of learning outcomes of Matthayomsueksa 4 students with different styles of learning who learned using the Web-based courseware in Basic Information Technology 4 course. Unpublished Master's thesis-M.Ed. in Educational Technology, Mahasarakham University.

Uzuntiryaki, E. (2007). Learning styles and high school students' chemistry achievement. Science Education International, 18(1), 25-37.

Weiler, A. (2004). Information-seeking behavior in generation Y students: Motivation, critical thinking, and learning theory. The Journal of Academic Librarianship, 33, 46-53.

Wilson, T.D. (2000). Human information behavior. Information Research, 3, 49-55.

Wilson, T.D. (1981). On user studies and information needs. Journal of Documentation, 37(1), 3-15.

Wilson, T.D. (1997). A critical review information behaviour: An interdisciplinary perspective. Information Processing \& Management, 33, 551-572.

Wilson, T.D. (1999). Models in information behaviour research. Journal of Documentation, $55,249-270$.

Wilson, T.D. (2005). Evolution in information behavior modeling: Wilson's model. In K. Fisher, S. Erdelez \& L. McKechnie (Eds.), Theories of information behavior (pp. 3136). Medford, NJ: Information Today.

Wilson, T.D. (2007). Recent trends in user studies: Action research and qualitative methods. Information Research, 5(3). Retrieved October 20, 2014, from http://informationr.net/ir/5-3/paper76.html 